Can pragmatic inference benefit from topic prominence? ERP evidence from Mandarin Chinese

Corresponding Author

Order of Authors xiaodong $\mathrm{xu}$

Lijuan Chen, xiaodong xu, Qingrong Chen, Phaedra Royle

Submission $\square$ Files $\square$ Included $\square$ in $\square$ this $\square$ PDF 


\begin{abstract}
This study investigated how pragmatic inference making is modulated by information structure in preceding text. We created three types of two-clause structures in which the interpretation of a critical word in the second clause was dependent on the engagement of pragmatic inference as well as a successful establishment of a referential relation between the target word and an intended antecedent in the preceding text. An enhanced P600 response was elicited by target words when the intended referent was in non-topic position compared to topic position or sub-topic position. Moreover, a reduced N400 was elicited by the target word when the intended referent in the preceding clause was in non-topic position, compared to topic position. These findings suggest that the process of building an inferential relation can benefit from information structural prominence of topicality.
\end{abstract}

Keywords: topic, information structure, pragmatic inference, N400, P600 


\title{
Can pragmatic inference benefit from topic prominence? ERP evidence from Mandarin Chinese
}

\author{
Lijuan Chen ${ }^{a}$, Xiaodong Xu ${ }^{a}$, Qingrong $C_{h e n^{b}} \&$ Phaedra Royle ${ }^{c}$, \\ a School of Foreign Languages and Cultures, Nanjing Normal University, \\ Nanjing 210097, China

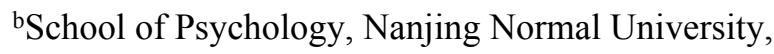 \\ Nanjing 210097, China \\ ${ }^{\mathrm{c}}$ École d'orthophonie et d'audiologie, Université de Montréal.
}

Address Correspondence to

Dr. Xiaodong $\mathrm{Xu}$,

School of Foreign Languages and Cultures, Nanjing Normal University, Nanjing 210097, China

Email: 412alix@gmail.com

or Dr. Qingrong Chen

Email : psycqr@163.com 


\begin{abstract}
This study investigated how pragmatic inference making is modulated by information structure in preceding text. We created three types of two-clause structures in which the interpretation of a critical word in the second clause was dependent on the engagement of pragmatic inference as well as a successful establishment of a referential relation between the target word and an intended antecedent in the preceding text. An enhanced P600 response was elicited by target words when the intended referent was in non-topic position compared to topic position or sub-topic position. Moreover, a reduced N400 was elicited by the target word when the intended referent in the preceding clause was in non-topic position, compared to topic position. These findings suggest that the process of building an inferential relation can benefit from information structural prominence of topicality.
\end{abstract}

Keywords: topic, information structure, pragmatic inference, N400, P600 


\section{Introduction}

During communication, speakers want their utterance to be appropriately interpreted. However, there is almost always more information conveyed than actually said. In many cases, the ideas expressed by a speaker may not be explicitly stated. Under such circumstances, an inferential process is initiated to bridge a current idea with a prior statement. Bridging inference is such a device by virtue of which pragmatic enrichment takes place and discourse coherence is achieved (Irmer, 2009). For instance, in sentence (1), there is no explicit antecedent for the referential expression "the black swan", its interpretation, therefore, must be retrieved from the explicit statement of a related entity "a ballet".

(1) I went to see a ballet last night. The Black Swan was marvelous.

A world knowledge-based inferential process enables the listeners to access the assumption that the name of the ballet is called "The Black Swan". In such cases, the generation of pragmatic inferences can greatly facilitate the process of establishing a situational model, though extra processing cost is required. A number of empirical studies have been carried out to examine the relationship between inferential process and on-line sentence processing (Bettinsoli, Maass, Kashima, \& Suitner, 2015; Burkhardt, 2006; Hirotani \& Schumacher, 2011; Kuperberg, Paczynski, \& Ditman, 2011; Yang, Perfetti, \& Schmalhofer, 2007). These studies, however, have mainly focused on how the different degrees of semantic association affect the establishment of pragmatic inference. Unlike these studies, the main purpose of our study is to shed light on how pragmatically-based information status (e.g., topichood vs. objecthood) affects inference making during sentence comprehension. Before we present our design, we first introduce the concept of topic and its relation with discourse coherence. Then we review the literature on the electrophysiological correlates of pragmatic inference during sentence processing, as well as on how inference making is modulated by semantically- and structurally-based constraints. 


\subsection{The notion of topic and discourse coherence}

The information status of discourse constituents is conceived as a gradient representation of discourse salience that is attributed to information structural notions such as topic-comment and given-new (Burmester et al., 2014). Topic is defined as the most prominent sentence/discourse entity indicating what the utterance is about, and establishing shared information between the speaker and the addressee (i.e., givenness; Li \& Thompson, 1989; Reinhart, 1981). Structurally, a topic tends to be associated with an early and prominent syntactic position, i.e., the highest position in a syntactic tree (Cowles \& Ferreira, 2011; Lambrecht, 1994; Xu \& Zhou, 2016), which is typically a noun phrase (NP) subject (an object can also be topicalized) that names what the clause/sentence is about. At the discourse level, topic encodes the discourse-pragmatic notion of aboutness and relevance, in addition to definiteness and givenness (Colonna, Schimke, \& Hemforth, 2012; Lambrecht, 1994; Reinhart, 1981). In particular, as the first element of a sentence, topic provides an anchoring point from which an upcoming referential expression is inferred and hence defines the perspective from which the reader/hearer will process the following utterance (Vallduvi \& Engdahl, 1996), and therefore is more accessible in the reader/listener' mental model relative to other non-topic entities (e.g., object). Given its prominent status in discourse, a topic entity is argued to be highly accessible as an indirect antecedent for bridging inference (Matsui, 1993). A topic entity is normally a preferential candidate for the subsequent referential expression (co-reference) and topic continuation is regarded as an important principle to maintain discourse coherence during both utterance comprehension (Stevenson, Nelson, \& Stenning, 1995; Cowles, Walenski, \& Kluender, 2007; Kaiser, 2011) and production (Cowles \& Ferreira, 2011).

\subsection{Electrophysiological correlates of pragmatic inference}

The involvement of pragmatic inference during sentence comprehension can facilitate the construction of a coherent discourse representation, and lead to faster and better comprehension performance. Electrophysiological studies have shown an 
attenuated N400 (a negative deflection between 300-500 ms post onset of a target word that is linked, among other things, to lexical-semantic integration) for sentences where pragmatic inference was straightforward, as compared to those where such processes were difficult or impossible (Hirotani \& Schumacher, 2011; Kuperberg et al., 2011), suggesting that the process of establishing a coherent sentence representation can benefit from pragmatic inference. Nonetheless, the N400 has also been interpreted to reflect memory (lexical semantic) retrieval (Brouwer, Fitz, \& Hoeks, 2012; Federmeier \& Kutas, 1999; Federmeier \& Laszlo, 2009; Kutas \& Federmeier, 2011), with its (smaller) size reflecting the ease with which lexical information is retrieved from the semantic memory system.

However, although pragmatic inference can facilitate sentence comprehension, making a pragmatic inference is not itself without cost, it slows down sentence processing, as it takes extra time and cognitive resources (e.g., working memory capacity, Clark \& Sengul, 1974; Haviland \& Clark, 1974; Van den Broek, Beker, \& Oudega, 2015). For instance, Yang et al. (2007) observed a larger N400 in response to a target word when its interpretation was dependent on an inferential process (e.g., "... the bomb hit the ground. The explosion...") than when morphological (their term is "referentially explicit" e.g., "... the bomb hit the ground and exploded. The explosion...”) or conceptual associations existed between them (e.g., “... the bomb hit the ground and blew up. The explosion...”). Difficulties in establishing pragmatic inference during sentence processing have also been reflected by the P600 (e.g., Burkhardt, 2006; Davenport \& Coulson, 2011), a late positivity which was initially interpreted to reflect syntactic processing (Osterhout, Holcomb, \& Swinney, 1994; Osterhout, \& Mobley, 1995) and more recently has been described as reflecting reinterpretation or updating of discourse representation (Brouwer, Fitz, \& Hoeks, 2012; Burkhardt, 2006; Hung \& Schumacher, 2012; Kaan, Dallas, \& Barkley, 2007; Steinhauer \& Connolly, 2008). Burkhardt (2007) measured ERPs on target words (e.g., 'pistol') following contexts which have different inferential relations with the target word (e.g., "Yesterday, a Ph.D. student was shot/killed/found dead/ downtown"), a larger positivity (P600) was obtained on target words when an 
inferential process was necessary (under 'killed' context) compared to cases in which they were not (the 'shot' context) due to the explicit semantic association, probably because processing an inferential reference requires more cognitive effort to update discourse model than processing an overt reference.

Pragmatic inference is subject to both lexical-semantic and structural constraints (Van den Broek, Beker, \& Oudega, 2015). In a number of recent studies (e.g., Burkhardt, 2006; Haviland \& Clark, 1974; Kuperberg et al., 2011; Stafura \& Perfetti, 2014; Stafura et al., 2015; Yang et al., 2007), semantic association across clauses/sentences was manipulated. Most of these studies adopted a word-to-text processing paradigm in which the integration of a target word of a second sentence/clause into the existing representation (i.e., the initial sentence/clause) was dependent on the degree to which the preceding sentence/clause contained an antecedent that had a semantic association with the target word. Using this paradigm combined with a meaning judgment task, Stafura and Perfetti (2014) examined how inference was modulated by different degrees of semantic association between a target word and the preceding text. While the target word (e.g., the "rain") was preceded either by a strongly (““..., dark clouds began to gather, and it started to storm. The rain ...”) or a weakly associated prime (“..., dark clouds began to gather, and it started to shower. The rain ...”), both resulted in reduced N400 responses relative to the baseline condition (in which the target word had no readily-available referent in the preceding text), a larger N400 reduction was observed in strong association conditions than weak association ones over some sites (e.g., left parietal electrodes), suggesting that pragmatic inference can benefit from semantic association. Moreover, the direction of the association can also affect pragmatic inference as well (Stafura et al., 2015). Backward association (from target to text, e.g., "when the bear was awoken by the wandering chipmunk, he was filled with anger. The rage ...",) resulted in larger P600, as well as N400, responses than the forward association (from text to target, e.g., "when the bear was awoken by the wandering chipmunk, he was filled with rage. The anger ...”). The ERP modulations were attributed to different load on memory system-backward inference is assumed to be 
less sensitive to memory capacity than forward inference.

Apart from semantic constraints, drawing pragmatic inference is also affected by structural constraints. In an off-line sentence comprehension task (e.g., how much do you think the action is due to the subject/object?), Bettinsoli et al. (2015) explored how word order variation influences causal interpretation of an event. Consistent with other studies (e.g., Kandylaki, 2011; Li \& Zhou, 2010), the authors found that participants were more likely to attribute the cause of an event (e.g., the teacher has criticized the student) to the element that occurs in the first rather than in later (2nd or 3rd) sentential positions, indicating a preferential causal attribution for the first over the second mentioned element, due to the more salient status of the sentence-initial than the sentence-medial elements in a sentence. More importantly, in one recent ERP study using a word-text processing paradigm, Burkhardt and Roehm (2007) investigated how inferential process is modulated by the structural salience of the contextual sentence. The target word (in sentence (3)) was preceded either by a salient structure (only one potential referent with no coordination) like (2a), or a less salient structure (two potential referents with coordination) like (2b). A more pronounced N400 was observed (on 'midwife') if the inferential relation involved a less salient referent (2b) compared to the inferential relation that contained a highly salient referent (2a). This seems to suggest that pragmatic inference can benefit from structural aspects of prominence ${ }^{1}$.

(2a) Gerhard/filmte/erstmals/eine Geburt/für /Arte. (with no coordination) Gerhard/filmed/for the first time/a delivery/for/Arte.

(2b) Erwin/filmte/erstmals/eine Geburt/und/eine Beerdigung. (with coordination) Erwin/filmed/for the first time/a delivery/and/a funeral.

(3) $\mathrm{Er} /$ berichtete,/dass/die Hebamme/äußerst/freundlich/war. (target sentence) He/reported/that/the midwife/extremely/friendly/was.

\footnotetext{
${ }^{1}$ However, as suggested by an anonymous reviewer it could also be that the difference between conditions is linked to the level of semantic richness they contained, as one condition contained one semantic element and the other two.
} 
It should be noted that the notion of structural constraint has a closer association with pragmatic than lexical-semantic information. In many cases, structural manipulations, such as word order variation, can lead to a change in an entity's pragmatic and information status, especially in languages with flexible word orders (e.g., Chinese, Xu, 2015; LaPolla, 1995, and Finnish, Järvikivi et al., 2005). However, up until now, the existing ERP studies were mainly concerned with how pragmatic inference is modulated by lexical-semantic associations or purely structural differences, it remains unclear how pragmatic inference is constrained by pragmatic information.

Taken together, the existing evidence from ERP studies indicate that inference making during sentence processing can facilitate the on-line establishment of a coherent mental representation. Drawing a pragmatic inference is also a strategic and resource-consuming mental operation, and is modulated by a number of constraints including semantic as well as structural factors. However, the existing studies were mainly concerned with how pragmatic inference is modulated by semantic association or structural difference, it remains unclear how pragmatic inference is modulated by pragmatically encoded information status, in particular that which is realized through structural manipulation.

\subsection{The present study}

In contrast to the above mentioned studies in which different levels of lexicalsemantic association between the target word and the preceding text were manipulated, the present study focused on how pragmatically-based information status influences the establishment of a bridging inferential relation. More specifically, we want to examine whether and how establishing inference during word-to-text integration process is modulated by the information status of an intended referent (e.g., topic antecedent vs. non-topic antecedent). To this end, we manipulated the information status of the referent while keeping the semantic associations between 
target and the intended antecedent completely constant.

Chinese is claimed to be a topic-prominent language (Li \& Thompson, 1976; 1989; Huang et al., 2009), in which topic-comment is a canonical information structure in addition to subject-verb-object (SVO) structure. As a topic-prominent language, Chinese uses topicalization to a greater degree than other non-topicprominent languages (Li, 1996). However, in contrast to other languages (e.g., German, Japanese) in which topic can be realized through morphological devices such as case marking (e.g., Hirotani \& Schumacher, 2011), topic information in Chinese is not realized morphologically. Instead, topichood in Chinese is typically indicated using pragmatic or discourse devices. In many situations, especially in the written form, topic is identified based on word order alone. For instance, although both sentence (4) and (5) are acceptable in Chinese, the NP, "the book" conveys different linguistic functions in (4) and (5). While “the book" (书) plays a patient role and acts as an object in (4), it acts as sentence topic in (5) even if it plays the same patient role. This is because "the book" is in the prominent sentence-initial position and is interpreted as the shared information between the speaker and the addressee in (5), but not in (4). It is thus assumed that the entity ("the book") is more salient in discourse in sentence (5) than in sentence (4).

（4）小王看完了书.

Xiaowang has read book (SVO)

Xiaowang has read the book.

（5）书小王看完了.

Book Xiaowang has read (OSV)

Xiaowang has read the book.

（6）小王书看完了.

Xiaowang book has read (SOV)

Xiaowang has read the book. 
Another important feature of Chinese topic structure is that Chinese can support more than one topic entity in a single sentence (Xu \& Liu, 2007). Taking sentence (6) as an example, in addition to the main topic (i.e., "Xiaowang") of the sentence, "the book" is regarded as the second topic (or sub-topic) of the sentence as it is in second position, before the verb "read", and it is also treated as the shared information between speaker and hearer (Xu, 2015; Xu \& Liu, 2007). As a consequence, "the book" (sub-topic) is believed to be more salient in sentence (6) than in sentence (4). According to Chao (1968), at least $50 \%$ of Chinese sentences can be analyzed as having topic-comment structure, in which a topic establishes a reference point upon which the rest of the sentence (i.e. comment) is centered. Thus, Chinese provides us with a good opportunity to test the influence of topic structure on sentence processing in more natural contexts than in other subject-prominent languages.

Similar to previous studies using word-to-text processing paradigms (e.g., Burkhardt, 2006; Stafura \& Perfetti, 2014; Yang et al. 2007), we created two-clause sentences which contained two critical words: an antecedent word in the first clause and a target word in the initial position of the second clause. The first clause distinguished three types of information structures (SVO, SOV, and OSV), with the intended antecedent (the Object) embedded in these clauses bearing three different types of information status (objecthood, sub-topichood, and topichood). According to the immediate integration hypothesis of sentence processing (Koornneef et al., 2006; Traxler, 1997; Yang et al., 2007), if information structure indeed affects the on-line establishment of a coherent mental representation, it should exert an immediate influence on the integration of the initial word of the second clause. Specifically, if inference making can benefit from topic prominence, the integration of the target word into the mental model would be easier in a topic referential sentence compared to a non-topic referential one, and even in sub-topic referential sentences compared to non-topic referential ones, and thus result in attenuated P600 responses in the former than the later cases. As for the N400 effect, we have two different predictions. According to the integration account (Hagoort et al., 2004; Kuperberg et al., 2011), 
topic-shift would lead to difficulties in semantic integration, and thereby gave rise to larger N400 responses for non-topic inferential sentences (i.e., SVO structure) compared to topic inferential sentences. Alternatively, according to the retrieval account (Brouwer et al., 2012), non-topic inferential sentences should elicit reduced N400 responses than topic inferential sentences, because the former is easier to retrieve than the later due to the benefits of a short-distance dependency.

Table 1. Experimental conditions and exemplar sentences with literal translations and glosses.

\begin{tabular}{ll}
\hline Conditions & \multicolumn{1}{c}{ Examples } \\
\hline Topic (7a). 早报/爷爷/已经读过了, 大火/得到了/控制. \\
Zaobao yeye yijing duguole, dahuo/dedaole/ kongzhi \\
Morning-newspaper/ Grandpa/ has-read, fire/ has-been/ put-out \\
Grandpa has read the Morning-newspaper; the fire has been put \\
out. \\
Sub-topic (7b). 爷爷/早报/已经读过了, 大火/得到了/控制. \\
Yeye zaobao yijing duguole, dahuo/dedaole/ kongzhi \\
Grandpa/ Morning-newspaper/ has-read, fire/ has-been/ put-out \\
Grandpa has read the Morning-newspaper; the fire has been put \\
out. \\
(7c). 爷爷/已经读过了/早报, 大火/得到了/控制. \\
Yeye yijing duguole zaobao, dahuo/dedaole/ kongzhi \\
Grandpa/ has-read/ Morning-newspaper, fire/ has-been/ put-out \\
Grandpa has read the Morning-newspaper; the fire has been put \\
out.
\end{tabular}

\section{Methods}

\subsection{Participants}

Thirty-eight native Chinese speakers from Nanjing Normal University, Nanjing, China participated in this study. The data from five participants were excluded due to EEG artifacts $(n=4)$, or because they did not complete the task $(n=1)$, resulting in 
33 participants in the final ERP data analyses (13 women, their age ranged from 19 to 28 years with a mean of 23.1 years). All of them were right-handed and had normal or corrected-to-normal vision. None of them had a history of neurological or psychiatric disorders. None had participated in stimuli development tasks described below. Participants gave informed consent before the experiment. This study was carried out in accordance with the Declaration of Helsinki and was approved by the Ethics Committee of the Nanjing Normal University.

\subsection{Design and materials}

Ninety triplets of two-clause sentences were constructed, as illustrated in Table 1. For each triplet, the target clause (second clause) was kept identical in all three conditions, whereas the initial clause has identical constituents but their order of mention was not the same, due to the manipulation of the information status of the critical antecedent (e.g., Morning newspaper). Specifically, the intended antecedent (of the target) embedded in the initial clause can occur either in sentence-initial position, sentence-medial position or sentence-final position, and correspondingly functions as the topic, the sub-topic and the non-topic (i.e., object), as demonstrated in 7(a), 7(b), and 7(c), respectively (Xu \& Liu; 2007). Note however that although the initial (target) word of the second clause ("the fire") had no explicit semantic/lexical association with the constituents in the preceding clause, it could be linked with the intended antecedent and the preceding text by drawing a pragmatic inference, since there was an indirect referential relation between the target and the intended antecedent (based on real world knowledge and context). For each condition, the successful integration of the target word of the second clause into the existing discourse representation depended on the generation of an inference to bridge the gap between the target and the meaning of the preceding text. In particular, integration difficulty was expected to be largely dependent on the degree to which a pragmatic inference was generated, which, in turn, was mainly constrained by the information status of the intended referent. 
For the ERP experiment, each experimental sentence in a triplet was assigned to a different testing list with a Latin-square design, such that each list had 30 different sentences per condition and each subject see only one sentence of each triplet. Moreover, in order to encourage the reader to read the sentence naturally without developing strategies, 180 filler sentences were constructed, including 150 sentences with similar two-clause structures as the experimental conditions (with the initial clause having either SVO, SOV, or OSV structure) but either a pronoun (120 sentences; e.g., she "Xiaoli lost her bank card, she didn't buy anything today") or a function word (30 sentences; e.g., then, but, once, etc.) occupied the initial position of the second clause, and 30 sentences in which there was a close semantic association between the critical word and the potential referent (e.g., The patient was in low spirits, the doctor encouraged her to cheer up). All sentences in each list were pseudorandomized, with the restriction that no more than three consecutive sentences were of the same type and no more than three consecutive sentences were expected to generate a "yes" or "no" response (see Procedures below).

The stimulus materials underwent three separate pretests, including a semantic association judgment test (forced choice test), a sentence completion test, and a sentence acceptability rating test. The forced choice and the sentence completion tests were developed to test (1) whether bridging inference was engaged after onset of the target words, and (2) the potential association between the target word and the preceding context (e.g., NP1, NP2, and the initial clause). In both tests, the first clause as well as the target word of the second clause was presented as a whole, while the sentence constituents after the target noun were deleted. In the forced-choice test, thirty-three participants were randomly assigned one of three counterbalanced lists (with only one of the three conditions for a given target). They were asked to select the antecedent noun that is most closely related to the target word. Three choices were provided, namely the initial noun (NP1), the second noun (NP2), and a third noun not mentioned in the context (a person or a thing). In the sentence completion test another thirty-two participants were asked to write a meaningful continuation to the fragment of each testing sentence. There was no time or word limit, but the completed 
sentences were to be as natural and reasonable as possible. The completion responses were coded into three types: mainly related with (1) the inanimate object-noun in the initial clause (e.g., 老赵租好了办公室, 地板是红色的/Laozhao has rented an office, the carpet is red.); (2) the whole initial clause (e.g., 小明从来不玩电脑, 游 戏容易上瘾/Xiao Ming never uses computers; the games are easily addictive.); (3) other words/sentences not explicitly mentioned in the text (e.g., 小明从来不玩电 脑, 游戏也不玩/Xiao Ming never uses computers, the games he doesn't play either.). Compared with the forced choice test, the sentence completion test is less influenced by task and therefore is more ecological.

Results from the forced choice test (see Table 2) showed that the target nouns of the second clause were more closely related with the object referent (inanimate noun) than either the subject referent (i.e., animate noun, OSV: $t(32)=5.23, p<0.001$; SOV: $t(32)=7.26, p<0.001$; SVO: $t(32)=7.77, p<0.001)$ or the outside-context referent (OSV: marginally significant, $t(32)=1.64,0.05<p<0.1$; SOV: $t(32)=2.97$, $p<0.01$; SVO: $t(32)=3.1, p<0.01)$. The percentage of subject reference or outsidecontext reference, however, was not different across conditions (for subject reference, $p \mathrm{~s}>0.3$; for outside-context reference, $p \mathrm{~s}>0.6$ ), although the percentage of object reference was larger in OSV sentence than in SVO sentence $(p<0.05)$, suggesting that the possibility of linking the target noun with the outside-context referent (the possibility of drawing outside-context inference) was equal across conditions.

Table 2. Percentage linking of the target noun with the inanimate object-noun, the animate subject-noun, or a third unmentioned referent in the forced choice test.

\begin{tabular}{lccc}
\hline & object-noun & subject-noun & outside-context referent \\
\hline Topic & $0.46 \pm 0.19$ & $0.19 \pm 0.18$ & $0.35 \pm 0.23$ \\
Sub-topic & $0.51 \pm 0.18$ & $0.16 \pm 0.16$ & $0.33 \pm 0.20$ \\
Non-topic & $0.52 \pm 0.19$ & $0.16 \pm 0.16$ & $0.32 \pm 0.22$ \\
\hline
\end{tabular}


Table 3. The possibility (percentage) of linking the second clause with the inanimate object-noun in the initial clause, the whole initial clause, or other words/sentences not explicitly mentioned in the text in the sentence completion test.

\begin{tabular}{lccc}
\hline & object-noun & whole clause & other words/sentences \\
\hline Topic & $0.31 \pm 0.12$ & $0.56 \pm 0.16$ & $0.09 \pm 0.10$ \\
Sub-topic & $0.32 \pm 0.14$ & $0.52 \pm 0.16$ & $0.14 \pm 0.13$ \\
Non-topic & $0.35 \pm 0.15$ & $0.58 \pm 0.14$ & $0.06 \pm 0.08$ \\
\hline
\end{tabular}

Results from the sentence-completion task in Table 3 show that the completion of the second clause was more likely related with the whole first clause (e.g., Grandpa has read the Morning-newspaper) rather than a single referent, i.e., the object noun (e.g., Morning-newspaper), in all three conditions. Pair-wise $t$-tests from the sentence completion test failed to show differences across the three conditions, neither for linking the target to the whole clause ( $p \mathrm{~s}>0.5$ ), nor for linking it to the single object noun $(p s>0.7)$, suggesting that the probability of drawing pragmatic inference in these three conditions is the same. Thus, readers continue the sentences based on the entire sentence rather than individual words (i.e., inanimate object nouns). This result differs from those found in the forced choice test, which showed that the target word was most closely related with the inanimate noun. Both lines of evidence suggest that although the target words are most closely related to the inanimate nouns (object noun), readers tend to connect the target word with the whole preceding clause rather than a single word. This means that the interpretation of the target word depends on bridging inference to link it with the existing event representation rather than the purely lexical semantic association between the target word and a given antecedent.

Additionally, in order to examine to what extent each of the experimental sentences was acceptable, an off-line sentence acceptability test was conducted prior to the ERP experiment. For this task, the critical sentences, together with filler sentences, were divided into three versions using a Latin-square procedure. Twentyfour students were randomly assigned to one of the three versions and were asked to 
judge the acceptability of each of the sentences using a 7-point Likert Scale (1 indicating the least acceptable and 7 indicating the most acceptable). The mean acceptability score for experimental stimuli was $4.7(\mathrm{SD}=1)$ for the OSV sentences, $4.3(\mathrm{SD}=1)$ for the SOV sentences, and $5.2(\mathrm{SD}=0.8)$ for the SVO sentences. Repeated measures ANOVA showed a significant main effect of experimental condition, $F(1,23)=15.28, p<0.001$. Post-hoc pair-wise comparisons showed that SVO sentences were more acceptable than either the OSV sentences, $t(23)=2.85, p<$ 0.03 , or the SOV sentences $t(23)=5.2, p<0.01$. Moreover, OSV sentences were more acceptable than SOV ones $t(23)=3.0, p<0.03$.

\subsection{Procedures}

Participants sat in a comfortable chair in a dimly lit room and were instructed to read each sentence carefully. Each trial began with a fixation cross ('+') at the center of the screen for $500 \mathrm{~ms}$, followed by a blank screen for $500 \mathrm{~ms}$. Then the initial clause was presented on the screen (the screen included the entire clause). After reading the first clause, the participant immediately pressed the space bar to initiate the second clause, which was presented word-by-word at the center of the screen. Each segment was presented for $400 \mathrm{~ms}$ followed by a $400 \mathrm{~ms}$ blank screen. The final segment of each sentence was followed by a yes/no comprehension question that probed sentence comprehension (e.g., "Has the fire been put out?"). Assignment of left/right hands to yes/no responses was counterbalanced across participants.

Participants performed a practice block of 20 sentences that had similar structures as the test stimuli. In the experiment, the test stimuli were divided into four blocks and the participant had an average break of about three minutes between each block. The whole experiment lasted about 2.5 hours on average, including electrode installation.

\subsection{EEG recording and data analysis}

EEG activity was recorded from 63 electrodes in a secured elastic cap (Electro-cap International) and Electrode impedances were kept below $5 \mathrm{k} \Omega$. The 
EEGs were referenced online to the tip of nose and re-referenced offline to the algebraic average activity measured in the left and right mastoids (TP9 and TP10). The vertical electrooculogram (VEOG) was monitored from electrodes located above the right eye and the horizontal electrooculogram (HEOG) from electrodes located at the outer canthus of the left eye. EEG signals were filtered using a bandpass of 0.016$70 \mathrm{~Hz}$, and digitized at a sampling rate of $500 \mathrm{~Hz}$. Trials with absolute values greater than $60 \mu \mathrm{V}$ were excluded from further analysis. Trials with ocular artifacts were corrected using independent component analysis (ICA) approach (Jung et al., 1998; Makeig, Bell, Jung, \& Sejnowski, 1996).

For each sentence, a $900 \mathrm{~ms}$ ERP epoch was extracted for the initial word of the second clause (e.g. "fire"). As the difference in word-order prior to the target, a 0.1-20 Hz band-pass filter rather than the pre-stimulus baseline correction was adopted. Trials with incorrect responses were eliminated from data analysis, and the remainder were screened for drift artifacts. The mean number of trials included for EEG analysis was 27.9 for the topic condition, 28.5 for the sub-topic condition, and 28.2 for the non-topic condition. There was no significant difference between conditions, $p \mathrm{~s}>0.1$

On the basis of visual inspection as well as the previous literature concerning inferential processing (e.g., Burkhardt, 2006; Cohn \& Kutas, 2015; Dröge et al., 2016; $\mathrm{Xu}$, Jiang, \& Zhou, 2015), the $350-450 \mathrm{~ms}$ as well as $450-800 \mathrm{~ms}$ time windows were selected for statistical analysis of the N400 and P600 components. Analyses of variance (ANOVAs) were conducted on mean ERP amplitudes in these two time windows, with experimental condition (topic, sub-topic, and non-topic), and topographical factors as within-participant variables. For the midline analysis, the topographic factor was region [three levels: anterior $(\mathrm{Fz}$ and $\mathrm{FCz})$, central $(\mathrm{Cz}$ and $\mathrm{CPz}$ ), and posterior ( $\mathrm{Pz}$ and $\mathrm{POz})]$. For the lateral analysis, the topographic factor was region (three levels: anterior vs. central vs. posterior) and hemisphere (two levels: left vs. right). The factors region and hemisphere were crossed, resulting in six regions of interest: left frontal (F1, F3, F5, FC1, FC3 and FC5), left central (C1, C3, C5, CP1, 
$\mathrm{CP} 3$ and $\mathrm{CP} 5)$, left posterior (P1, P3, P5, PO3, and PO7), right frontal (F2, F4, F6, FC2, FC4 and FC6), right central (C2, C4, C6, CP2, CP4 and CP6) and right posterior (P2, P4, P6, PO4, and PO8). Mean amplitudes over electrodes in each region of interest were entered into ANOVAs. Post-hoc comparisons with Bonferroni correction were carried out and the Greenhouse-Geisser correction was performed when appropriate.

\section{Results}

\subsection{Behavioral results}

Average comprehension question accuracy was $98.7 \%($ Mean $=29.5, \mathrm{SD}=0.86)$ for the topic-referential condition, $98.8 \%($ Mean $=29.6, \mathrm{SD}=0.55)$ for the sub-topic referential condition, and 97.6\% $($ Mean $=29.3, \mathrm{SD}=1.12)$ for the non-topic referential condition. An ANOVA with experimental condition as a within-subject factor failed to show any significant effect of condition, $F(2,64)=2.02, p>0.1$, suggesting that participants can process these sentences equally well.

\section{Insert Figs. 1 and 2 about here}

\subsection{ERP results}

The grand averaged ERPs, time-locked to the target words, are shown in Figure 1. As can be seen in Figure 1, target words in the non-topic condition elicited a larger P600 compared to those in the topic condition or sub-topic condition. Additionally, a reduced N400 was elicited by the target word when the intended referent in the preceding clause was in non-topic position, compared to topic position. The scalp topographies in Figure 2 depict the differences on the target words between the nontopic and the topic/sub-topic conditions, as well as between the sub-topic and the topic conditions in the $450-800 \mathrm{~ms}$ time window. 


\section{0-450 ms time window (N400)}

Mean amplitudes recorded at the lateral and midline electrodes were analyzed separately. Repeated-measures ANOVAs with condition, region and hemisphere as within-subject variables showed a significant main effect of condition [lateral: $F(2,64)$ $=3.16, p<0.05, \eta^{2}=0.09$; midline: $\left.F(2,64)=2.34,0.05<p<0.1, \eta^{2}=0.07\right]$. No other interesting effects were significant.

Follow-up pairwise-comparisons showed that the non-topic condition induced a reduced N400 than the topic condition [lateral: $t(32)=2.46, p<0.05$; midline: $t(32)=$ $1.96,0.05<p<0.1]$ but not the sub-topic condition $p \mathrm{~s}>0.1$.

\section{0-800 ms time window (P600)}

Repeated-measures ANOVA with condition, region, and hemisphere (only in the lateral analysis) as within-subject variables showed a significant main effect of condition [lateral: $F(2,64)=6.49, p<0.005, \eta^{2}=0.17$; midline: $F(2,64)=6.01, p<$ $\left.0.005, \eta^{2}=0.16\right]$. No other interesting effects were significant $p \mathrm{~s}>0.1$.

Follow-up pairwise-comparisons showed that the non-topic condition elicited a larger P600 than either the topic condition [lateral: $t(32)=3.98, p<0.005$; midline: $t(32)=3.80, p<0.005$ ], or the sub-topic condition [lateral: $t(32)=2.46, p<0.05$; midline: $t(32)=2.36, p<0.05$ ], whereas there was no difference of P600 between the topic condition and the sub-topic condition $p \mathrm{~s}>0.3$.

\section{Discussion}

This study investigated the impact of information structure (topic structure vs. nontopic structure) on inference making during sentence comprehension. An enhanced P600 was observed at target words (NPs) when the intended referent in the preceding clause was in non-topic position compared to topic or sub-topic positions, when the potential interference from distance was excluded. In contrast, a reduced N400 was observed on the target word when the intended referent was in non-topic position, compared to topic position. These findings suggest that building an inferential relation 
during discourse processing can benefit from information structural prominence (topichood).

\subsection{N400 and semantic processing}

A larger N400 is observed in response to sentences with various types of semantic/or pragmatic incoherence (Kutas, 1980; Hagoort et al., 2004). The N400 has also been observed in situations where there is no semantic/pragmatic incoherence but an inferential process has to be employed to build a coherent sentence representation (e.g., Burkhardt \& Roehm, 2007). The size of N400 effect was traditionally interpreted to reflect the relative difficulty of semantic integration processing (Hagoort et al., 2004; Kuperberg et al., 2011). Alternatively, the amplitude of N400 has also been interpreted as reflecting the ease of retrieving lexical information from long-term memory (Brouwer et al., 2012; Federmeier \& Kutas, 1999; Federmeier \& Laszlo, 2009). According to the later account, the more difficult the retrieval process, the larger of the N400 amplitude. As for the present study, given that the same critical word pairs (antecedent-target word) were used, the lexico-semantic information between the target word and the intended referent in preceding text remains identical across conditions. The difference in N400 amplitude, therefore, is less likely to be associated with the lexically-based integration process. In particular, according to the integration account, if the difference in N400 amplitude is associated with semantic integration, topic-inferential relations should result in reduced N400s relative to the non-topic inferential conditions, because integrating a semantically salient entity (topic) should be easier than integrating a semantically less salient entity (object). However, the fact that an enhanced, rather than a reduced N400, was found for topicinferential relations than non-topic-inferential ones goes against this explanation. Instead, the difference in N400 amplitude was more plausibly related to retrieval processing difficulties — that is, retrieving lexical information from long-term memory and linking it to the target word. Consistent with this interpretation, a number of ERP studies found a correlate between the N400 amplitude and the distance between an anaphora and its potential referent. For instance, Hammer et al. (2008) 
found that long-distance referential relations resulted in increased N400 responses in comparison with short-distance referential relations, due to the increased effort when linking a pronoun with a less accessible antecedent. In the same vein, in our study the establishment of a link was easier for non-topic referential relations than for topicreferential relations, because of the stronger activation of the antecedent in the shorter distance dependency than the long distance dependency, and thus resulted in a reduced N400 in the non-topic referential relation, compared to the topic referential relation.

\subsection{P600, pragmatic inference, and sentence integration processing}

In contrast to previous studies (Kuperberg et al., 2010; Yang et al., 2007), a sustained positivity (P600) in addition to an N400 was observed when participants were establishing a bridging inference. The P600 component has been found across languages for a large variety of linguistic anomalies including syntactic violations (Hagoort, Brown, \& Groothusen, 1993; Osterhout, \& Mobley, 1995; Xu, Jiang, \& Zhou, 2013), syntactic ambiguity (“garden path” sentences; Osterhout, Holcomb, \& Swinney, 1994), or even semantic violation (e.g., "The hearty meal was devouring..."; Kim, \& Osterhout, 2005), and has been interpreted to reflect repair or reanalysis. However, the P600 effect observed in this study cannot be grouped in this class of phenomena, since neither syntactic nor semantic anomalies/ambiguities were present. Instead, the P600 is more likely associated with ease of integration (Brouwer et al., 2012; Hoeks \& Brouwer, 2014; Wang \& Schumacher, 2013), namely integrating an indirectly (inferentially) associated relation into discourse. According to the integration account, the P600 amplitude is associated with the effort engaged to establish a coherent discourse representation, irrespective of whether there is an overt anomaly or not. The more demanding integration is, the larger the amplitude of the P600.

The observation of a P600, however, is inconsistent with a few previous studies concerning pragmatic inference in which only an N400 component was reported (Kuperberg et al., 2010; Yang et al., 2007; Nieuwland, 2013, but see Davenport \& 
Coulson, 2011 who observed a P600 in addition to an N400 when building a novel meaning mapping, e.g., the mapping between the concept cardboard box and boat in "The clever boys used a cardboard box as a boat, ..."). One interpretation for the observation of late positivity may be related with the manipulation of topic structure. Given its prominent status in discourse, the integration of a topic entity (given information) into discourse is less costly than integration of a non-topic entity (new information), since the later would lead to topic shift or topic incoherence. Previous studies have repeatedly shown that topic shift during sentence/discourse processing would give rise to P600 response, reflecting effort on updating the discourse model (Burkhardt, 2006; Hirotani \& Schumacher, 2011; Xu, 2015). Here, the topic inconsistency in the non-topic referential condition makes pragmatic inference more demanding, and hence generated a larger P600. To note, the P600 modulation cannot be explained by distance-based difference (e.g., difference in working memory load) between the target word and the referent, because, if distance matters, a smaller rather than larger P600 response should be observed at the non-topic target word, as a short referential dependency usually leads to attenuated rather than increased P600 response (Hammer et al., 2008; Xu et al., 2015). Furthermore, the P600 effect cannot be explained in terms of the differences in acceptability either. If sentence acceptability is the key factor, a reduced P600 response should be found for non-topic-referential sentences (e.g., SVO sentence) rather than the topic referential sentences, since the former are more acceptable than the later. However, the finding of an enhanced P600 for non-topic over topic referential sentences goes against this interpretation ${ }^{2}$. Finally, the P600 modulation cannot be attributed to the lexical semantic association between the target word and antecedent. First, at the lexical-level, the same word pairs (the same target-antecedent words) were used in each triplet of experimental materials. Second, at the sentence-level, the results from both the forced choice and the sentence

\footnotetext{
${ }^{2}$ As can be seen in Figure 1, although a tendency for a larger P600 for the sub-topic sentence compared to the topic sentence seems consistent with the acceptability account (OSV sentences are more acceptable than SOV ones), the difference between these two conditions did not reach significance.
} 
completion showed that the preceding context and the mention-order exert no influence on the semantic association between the target and the antecedent. This provided further evidence to support our arguments that the P600 modulation was mainly attributable to the discourse-level inference rather than purely lexical semantic association.

The larger P600 in non-topic-referential condition could be related to processing costs involved in establishing pragmatic inference while integrating the target word with the preceding text representation. As demonstrated previously, an enhanced P600 was regularly observed in situations where new discourse entities are introduced or bridging inference must be drawn to achieve discourse coherence, reflecting the increased processing costs in updating the discourse model (Burkhardt, 2006; Burmester et al., 2014; Hirotani \& Schumacher, 2011; Kaan et al., 2007; Xu et al., 2013). As for the present study, although inferential processes are required to establish a coherent mental model for all three experimental conditions, the cognitive effort needed for successful pragmatic inference is not equal. For topic referential sentences, given that the antecedent word (e.g., Xiaowang) occurs in the sentenceinitial position and is what the following utterance is about (i.e., aboutness), it is thus highly accessible in readers' mental model. A bridging inference under such circumstance can easily be established. For the non-topic referential sentence, however, the integration process may have been more difficult, because the antecedent word occurs in a less prominent sentence-final position and acts as a sentence object. Its accessibility status in discourse, therefore, is relatively lower than the initial NP (e.g., Morning newspaper in sentence 7a). This lower status increases the costs of bridging inference and consequently led to increased brain activities.

Previous ERP studies (Stafura \& Perfetti, 2014; Stafura et al., 2015) have shown that increased semantic association between the target word and the preceding text leads to an N400 reduction, because a stronger semantic association can facilitate pragmatic inference. However, the facilitation observed here cannot be based on a stronger semantic association, but rather is due to pragmatically-based information status, namely the more prominent status of topic entities over non-topic entities. 
Moreover, the present study is also different from Burkhardt and Roehm's (2007) study in which the referent's salience status was mainly realized through structural manipulation (a coordinate structure vs. non coordinate structure). While one referent was available in the non-coordinate structure, two were available in the coordinate structure. The referential ambiguity in coordinate structure may have significantly increased the costs of retrieval and thus resulted in an increased N400.

\subsection{The N400-P600 complex and neurolinguistic models of sentence processing}

The finding of both N400 and P600 components in response to pragmatic inference processing could be interpreted within the framework of two-stage models of sentence processing (e.g., Brouwer et al. 2012; Brouwer \& Hoeks, 2013). According to the Retrieval-Integration model proposed by Brouwer et al. (2012), sentence processing is composed of a memory retrieval process and a subsequent integration process. The retrieval process is reflected by the N400, which is modulated by the ease with which lexical/semantic information can be retrieved from long-term memory, and is followed by the integration of each constituent into a coherent syntactic and mental representation, which can be reflected by modulations of the P600. The short distance between the target word and the intended antecedent in the non-topic condition (relative to the topic condition) led to a stronger memory representation of the preceding referent. Consequently, the retrieval process was much easier in the non-topic condition than the topic one and thus resulted in a reduced N400. However, although retrieval processes can benefit from this short-distance, the integration process apparently did not. Instead, compared to the long-distance dependencies (the topic as well as sub-topic condition), the integration of shortdistance dependencies into the discourse representation was more demanding, because the non-topic referent is pragmatically as well as structurally less prominent in discourse than either the topic entity or the sub-topic entity. More effort was thus required to integrate the entities with the less salient information, resulting in a larger P600. This seems to indicate that information-structural prominence takes precedence over the linear effects in establishing inferential coherence. Thus, the final integration 
process benefits less from distance than from the information status of the referents.

\section{Conclusion}

By manipulating the information status of an intended antecedent of referential expressions, we examined how their interpretation was modulated by the information structure of an intended antecedent. While a reduced N400 was elicited by a referential expression when the intended referent was in non-topic position compared to topic position, an enlarged P600 was elicited by the referential expression when the intended referent was in non-topic position compared to topic or sub-topic positions. These findings suggest that the establishing inference can benefit in different ways from the status of information structure. 


\section{Acknowledgements}

This study was supported by grants from the Natural Science Foundation of China (31300929), the Natural Science Foundation of the Higher Education Institutions of Jiangsu Province (16KJD180003), and the project supporting the top-100 young leading researchers in Nanjing Normal University. It was also supported by the "Blue Project" for outstanding young teachers of Nanjing Normal University as well as by the Academic Development Priority Program of Jiangsu Higher Education Institutions awarded to School of Foreign Languages and Cultures, Nanjing Normal University. We thank Dr. Stephen Politzer-Ahles for his suggestions and comments concerning earlier versions of the manuscript. 


\section{References}

Bettinsoli, M. L., Maass, A., Kashima, Y., \& Suitner, C. (2015). Word-order and causal inference: The temporal attribution bias. Journal of Experimental Social Psychology, 60, 144-149. doi: 10.1016/j.jesp.2015.05.011

Brouwer, H., Fitz, H., \& Hoeks, J. (2012). Getting real about semantic illusions: Rethinking the functional role of the P600 in language comprehension. Brain Research, 1446, 127-143. doi: 10.1016/j.brainres.2012.01.055

Brouwer, H., \& Hoeks, J. C. J. (2013). A time and place for language comprehension: mapping the N400 and the P600 to a minimal cortical network. Frontiers in Human Neuroscience, 7:758. doi: 10.3389/fnhum.2013.00758

Burkhardt, P. (2006). Inferential bridging relations reveal distinct neural mechanisms: Evidence from Event-related brain potentials. Brain and Language, 98, 159-168. doi: $10.1016 /$ j.band1.2006.04.005

Burkhardt, P. (2007). The P600 reflects cost of new information in discourse memory. NeuroReport, 18(17), 1851-1854. doi:

10.1097/WNR.0b013e3282fla999

Burkhardt, P., \& Roehm, D. (2007). Differential effects of saliency: An event-related brian potential study. Neuroscience Letters, 413, 115-120. doi: 10.1016/j.neulet.2006.11.038

Burmester, J., Spalek, K., \& Wartenburger, I. (2014). Context updating during sentence comprehension: The effect of aboutness topic. Brain and Language, 137, 62-76. doi: 10.1016/j.band1.2014.08.001

Chao, Y. R. (1968). A Grammar of Spoken Chinese. Berkeley: University of California Press.

Clark, H. H., \& Sengul, C. J. (1974). In search of referents for nouns and pronouns. Memory and Cognition, 7(1), 35-41. doi: 10.3758/BF03196932

Cohn, N., \& Kutas, M. (2015). Getting a cue before getting a clue: Event-related potentials to inference in visual narrative comprehension. Neuropsychologia, 77, 267-278. doi: 10.1016/j.neuropsychologia.2015.08.026

Cowles, H. W., \& Ferreira, V. S. (2011). The influence of topic status on written and 
spoken sentence production. Discourse Processes, 49, 1-28. doi: $10.1080 / 0163853 X .2011 .635989$

Cowles, H. W., Walenski, M., \& Kluender, R. (2007). Linguistic and cognitive prominence in anaphor resolution: Topic, contrastive focus and pronouns. Topoi, 26, 3-18. doi: 10.1007/s11245-006-9004-6

Colonna, S., Schimke, S., \& Hemforth, B. (2012). Information structure effects on anaphora resolution in German and French: A crosslinguistic study of pronoun resolution. Linguistics, 50(5), 991-1013. doi: 10.1515/ling-2012-0031

Davenport, T., \& Coulson, S. (2011). Predictability and novelty in literal language comprehension: An ERP study. Brain Research, 1418, 70-82. doi: 10.1016/j.brainres.2011.07.039

Dröge, A., Fleischer, J., Schlesewsky, M., \& Bornkessel-Schlesewsky, I. D. (2016). Neural mechanisms of sentence comprehension based on predictive processes and decision certainty: Electrophysiological evidence from non-canonical linearizations in a flexible word order language, Brain Research, 1633, 149-166. doi: 10.1016/j.brainres.2015.12.045

Federmeier, K. D., \& Kutas, M. (1999). A rose by any other name: Long-term memory structure and sentence processing. Journal of Memory and Language, 41, 469-495.

Federmeier, K. D., \& Laszlo, S. (2009). Time for meaning: Electrophysiology provides insights into the dynamics of representation and processing in semantic memory. In B. H. Ross (Ed.), Psychology of Learning and Motivation, Volume 51 (pp 1-44). Burlington: Academic Press.

Hammer, A. H., Jansma, B. M., Lammers, M., \& Münte, T. F. (2008). Interplay of meaning, syntax and working memory during pronoun resolution investigated by ERPs. Brain Research, 1230, 177-191. doi: 10.1016/j.brainres.2008.07.004

Hagoort, P., Hald, L., Bastiaansen, M., \& Petersson, K. M. (2004). Integration of word meaning and world knowledge in language comprehension. Science 304, $438-441$.

Hagoort, P., Brown, C. M., \& Groothusen, J. (1993). The syntactic positive shift 
(SPS) as an ERP measure of syntactic processing. Language and Cognitive Processes, 8, 439-483. doi: 10.1080/01690969308407585

Haviland, S. E., \& Clark, H. H. (1974). What's new ? Acquiring new information as a process in comprehension. Journal of Verbal Learning and Verbal Behavior, 13, 512-521. doi: 10.1016/S0022-5371(74)80003-4

Hirotani, M., \& Schumacher, P. B. (2011). Context and topic marking affect distinct processes during discourse comprehension in Japanese. Journal of Neurolinguisitics, 24, 276-292. doi: 10.1016/j.jneuroling.2010.09.007

Hoeks, J., \& Brouwer, H. (2014). Electrophysiological research on conversation and discourse processing. In T. Holtgraves (Ed.), Oxford University handbook of language and social cognition (pp. 365-386). Oxford, UK: Oxford University Press.

Huang, C. T. J., Li, Y. H. A., \& Li, Y. (2009). The syntax of Chinese. Cambridge: Cambridge University Press.

Hung, Y. C. \& Schumacher, P. B. (2012). Topicality matters: Position specific demands on Chinese discourse processing. Neuroscience Letters, 511, 59-64. doi: 10.1016/j.neulet.2012.01.013

Irmer, M. (2009). Bridging inferences in discourse interpretation. Doctoral Dissertation, Leipzig.

Järvikivi J., van Gompel R. P., Hyönä j., Bertram R. (2005). Ambiguous pronoun resolution: contrasting the first-mention and subject-preference accounts. Psychological Science. 16, 260-264.

Jung, T. P., Humphries, C., Lee, T. W., Makeig, S., McKeown, M. J., Iragui, V., \& Sejnowski, T. J. (1998). Extended ICA removes artifacts from electroencephalographic recordings. Advances in Neural Information Processing Systems 10, 894-900.

Kaan, E., Dallas, A. C., \& Barkley, C. M. (2007). Processing bare quantifiers in discourse. Brain Research, 1146, 199-209. doi: 10.1016/j.brainres.2006.09.060

Kaiser, E. (2011). Focusing on pronouns: Consequences of subjecthood, pronominalisation, and contrastive focus. Language and Cognitive Processes, 
26, 1625-1666. doi: 10.1080/01690965.2010.523082

Kandylaki, K. D. (2011) Causality of the subject: event initiator and its effect on processing. Philipps University of Marburg.

Kim, A., \& Osterhout, L. (2005). The independence of combinatory semantic processing: Evidence from event-related potentials. Journal of Memory and Language, 52, 205-225. doi: 10.1016/j.jml.2004.10.002

Koornneef, A. W., \& Van Berkum, J. J. A. (2006). On the use of verb-based implicit causality in sentence comprehension: Evidence from self-paced reading and eye tracking. Journal of Memory and Language, 54, 445-465. doi: 10.1016/j.jml.2005.12.003

Kuperberg, G., Paczynski, M., \& Ditman, T. (2011). Establishing causal coherence across sentences: An ERP study. Journal of Cognitive Neuroscience, 23, 12301246. doi: 10.1162/jocn.2010.21452

Kutas, M., \& Hillyard, S. A. (1980). Reading senseless sentences: Brain potentials relfect semantic incongruity. Science, 207, 203-205.

Kutas, M., \& Federmeier, K. D. (2011). Thirty Years and Counting: Finding Meaning in the N400 Component of the Event-Related Brain Potential (ERP). Annual Review of Psychology, 62, 621-647. doi: 10.1146/annurev.psych.093008.131123

Lambrecht, K. (1994). Information structure and sentence form: Topic, focus, and the mental representation of discourse referents. Cambridge: Cambridge University Press.

LaPolla R. J. (1995). Pragmatic relations and word order in Chinese. In, P. Downing, \& M. Noonan (Eds.), Word Order in Discourse (pp. 297-329). Amsterdam: John Benjamins Publishing Company),

Li, W. D. (1996). Second language acquisition of topic-comment structures in Mandarin Chinese. Ph.D. Dissertation, University of Alberta.

Li, C. N., \& Thompson, S. A. (1976). Subject and topic: A new typology of language. In C. N. Li (Ed.), Subject and topic (pp. 457-489). New York, NY: Academic Press.

Li, C. N., \& Thompson, S. A. (1989). Mandarin Chinese: A functional reference 
grammar. Berkeley: University of California Press

Li, X., \& Zhou, X. (2010). Who is ziji? ERP responses to the Chinese reflexive pronoun during sentence comprehension. Brain Research, 1331, 96-104. doi: 10.1016/j.brainres.2010.03.050

Makeig, S., Bell, A. J., Jung, T. P., \& Sejnowski, T. J. (1996). Independent component analysis of electroencephalographic data. Advances in Neural Information Processing Systems, 8, 145-151.

Matsui, T. (1993). Bridging reference and the notion of 'topic' and 'focus'. Lingua, 90, 49-68.

Nieuwland, M. S. (2013). "If a lion could speak ...": Online sensitivity to propositional truth-value of unrealistic counterfactual sentences. Journal of Memory and Language, 68, 54-67. doi: 10.1016/j.jml.2012.08.003

Osterhout, L., Holcomb, P. J., \& Swinney, D. A. (1994). Brain potentials elicited by garden-path sentences: evidence of the application of verb information during parsing. Journal of Experimental Psychology: Learning, Memory and Cognition, 20(4), 786-803.

Osterhout, L., \& Mobley, L. A. (1995). Event-related brain potentials elicited by failure to agree. Journal of Memory and Language, 34, 739-773. doi: 10.1006/jmla.1995.1033

Reinhart, T. (1981). Pragmatics and linguistics, an analysis of sentence topics. Philosophica, 27, 53-94.

Stafura, J. Z., Rickles, B., \& Perfetti, C. A. (2015). ERP evidence for memory and predictive mechanisms in word-to-text integration. Language, Cognition and Neuroscience, 30(10), 1273-1290. doi: 10.1080/23273798.2015.1062119

Stafura, J. Z., \& Perfetti, C. A. (2014). Word-to-text integration: Message level and lexical level influences in ERPs. Neuropsychologia, 64, 41-53. doi: 10.1016/j.neuropsychologia.2014.09.012

Steinhauer, K., \& Connolly, J. F. (2008). Event-related potentials in the study of language. In B. Stemmer \& H. A. Whitaker (Eds.), Handbook of the Cognitive Neuroscience of Language (pp. 91-104). New York: Elsevier. 
Stevenson, R. J., Nelson, A. W. R., \& Stenning, K. (1995). The role of parallelism in strategies of pronoun comprehension. Language and Speech, 38(4), 393-418. doi: $10.1177 / 002383099503800404$

Traxler, M. J., Bybee, M. D., \& Pickering, M. J. (1997). Influence of connectives on language comprehension: Eye-tracking evidence for incremental interpretation. The Quarterly Journal of Experimental Psychology, 50, 481-497. doi:10.1080/027249897391982

Vallduvi, E., \& Engdahl, E. (1996). The linguistic realization of information packaging. Linguistics, 34, 459-519.

Van den Broek, P., Beker, K., \& Oudega, M. (2015). Inference generation in text comprehension: Automatic and strategic processes in the construction of a mental representation. In E. J. O'Brien, A. E. Cook \& R. F. Lorch (Eds.), Inferences during reading (pp. 94-121). Cambridge, UK: Cambridge University Press.

Wang, L., \& Schumacher, P. B. (2013). New is not always costly: Evidence from online processing of topic and contrast in Japanese. Frontiers in Psychology, 4, 1-20. doi: 10.3389/fpsyg.2013.00363

Xu, L. J., \& Liu, D. Q. (2007). Topic structure and function (in Chinese). Shanghai: Shanghai Education Press.

$\mathrm{Xu}, \mathrm{X}$. D. (2015). The influence of information status on pronoun resolution in Mandarin Chinese: evidence from ERPs. Frontiers in Psychology, 6, 873. doi: 10.3389/fpsyg.2015.00873.

Xu, X. D., Jiang, X. M., \& Zhou, X. L. (2013). Processing biological gender and number information during Chinese pronoun resolution: ERP evidence for functional differentiation. Brain and Cognition, 81, 223-236. doi: 10.1016/j.bandc.2012.11.002

Xu, X. D., Jiang, X. M., \& Zhou, X. L. (2015). When a causal assumption is not satisfied by reality: differential brain responses to concessive and causal relations during sentence comprehension. Language, Cognition and Neuroscience, 30(6), 704-715. doi: 10.1080/23273798.2015.1005636 
Xu, X. D., \& Zhou, X. L. (2016). Topic shift impairs pronoun resolution during sentence comprehension: Evidence from event-related potentials.

Psychophysiology, 53, 129-142. doi: 10.1111/psyp.12573

Yang, C. Y., Perfetti, C. A., \& Schmalhofer, F. (2007). Event-related potential indicators of text integration across sentence boundaries. Journal of

Experimental Psychology: Learning, Memory, and Cognition, 33(1), 55-89. doi: $10.1037 / 0278-7393.33 .1 .55$ 


\section{Appendix 1: Examples of experimental materials with glosses}

(1c) 周勇抛售了股票，贷款即将到期。

Zhouyong has sold the stock; the loan needs to be repaid.

(1a) 股票周勇抛售了，贷款即将到期。

The stock Zhouyong has sold; the loan needs to be repaid.

(1b) 周勇股票抛售了，贷款即将到期。

Zhouyong the stock has sold; the loan needs to be repaid.

(2c) 老王从来不喝烈性酒, 酒精肝特别难治。

Laowang never drinks hard liquor; cirrhosis of the liver is particularly difficult to cure.

（2a）烈性酒老王从来不喝, 酒精肝特别难治。

Hard liquor Laowang never drinks; cirrhosis of the liver is particularly difficult to cure.

（2b）老王烈性酒从来不喝，酒精肝特别难治。

Laowang hard liquor never drinks; cirrhosis of the liver is particularly difficult to cure.

(3c) 王霞尚未发表过论文，职称仍然无望。

Wang Xia has not yet published papers; the titles are still hopeless.

（3a）论文王霞尚未发表过，职称仍然无望。

Papers Wang Xia has not yet published; the titles are still hopeless.

(3b) 王霞论文尚未发表过，职称仍然无望。

Wang Xia papers has not yet published; the titles are still hopeless.

(4c) 宏飞拿到了包裹, 手机是金色的。

Hongfei got the parcel; the phone is golden.

(4a) 包裹宏飞拿到了, 手机是金色的。

The parcel Hongfei got; the phone is golden.

(4b) 宏飞包裹拿到了，手机是金色的。

Hongfei the parcel got; the phone is golden. 
（5c）老钱已经办齐了年货, 红酒还是外国牌子的。

Laoqian has bought the Spring Festival goods; the red wine is a foreign brand.

（5a）年货老钱已经办齐了, 红酒还是外国牌子的。

The Spring Festival goods Laoqian has bought; the red wine is a foreign brand.

（5b）老钱年货已经办齐了, 红酒还是外国牌子的。

Laoqian the Spring Festival goods has bought; the red wine is a foreign brand.

(6c) 王芳特别爱吃猕猴桃, 维生素特别丰富。

Wangfang is particularly fond of kiwi; (because) vitamins are particularly rich.

(6a) 猕猴桃王芳特别爱吃, 维生素特别丰富。

Kiwi Wangfang is particularly fond of; (because) vitamins are particularly rich.

(6b) 王芳猕猴桃特别爱吃, 维生素特别丰富。

Wangfang kiwi is particularly fond of; (because) vitamins are particularly rich.

（7c）小明从来不玩电脑, 游戏容易上瘾。

Xiao Ming never uses computers; the games are easily addictive.

（7a）电脑小明从来不玩, 游戏容易上瘾。

Computers Xiao Ming never uses; the games are easily addictive.

（7b）小明电脑从来不玩, 游戏容易上瘾。

Xiao Ming computers never uses; the games are easily addictive.

(8c) 爸爸已经缴过了电费, 网银非常方便。

Dad has paid the electricity bill; online banking is very convenient.

(8a) 电费爸爸已经缴过了, 网银非常方便。

The electricity bill Dad has paid; online banking is very convenient.

(8b) 爸爸电费已经缴过了, 网银非常方便。

Dad the electricity bill has paid; online banking is very convenient.

(9c) 许娇已经找到了工作, 华为待遇非常诱人。 
Xujiao has found a job; Huawei (a famous company) is very attractive.

(9a) 工作许娇已经找到了, 华为待遇非常诱人。

A job Xujiao has found; Huawei (a famous company) is very attractive.

（9b）许娇工作已经找到了, 华为待遇非常诱人。

Xujiao a job has found; Huawei (a famous company) is very attractive.

(10c) 凯莉收到了生日礼物, 丝巾特别漂亮。

Kelly received a birthday gift; the scarf is particularly beautiful.

(10a) 生日礼物凯莉收到了, 丝巾特别漂亮。

A birthday gift Kelly received; the scarf is particularly beautiful.

(10b) 凯莉生日礼物收到了, 丝巾特别漂亮。

Kelly a birthday gift received; the scarf is particularly beautiful. 


\section{Figure Captions}

Figure 1. Grand average ERPs time-locked to the onset of the target words in the second clause for the topic condition, sub-topic condition, and non-topic condition.

Figure 2. Topographic maps for the difference waves resulting from the subtractions of ERPs for topic condition from that for non-topic condition (a), ERPs for subtopic condition from that for non-topic condition (b), and ERPs for topic condition from that for sub-topic condition (c) in the 450 - $800 \mathrm{~ms}$ time window, respectively. 

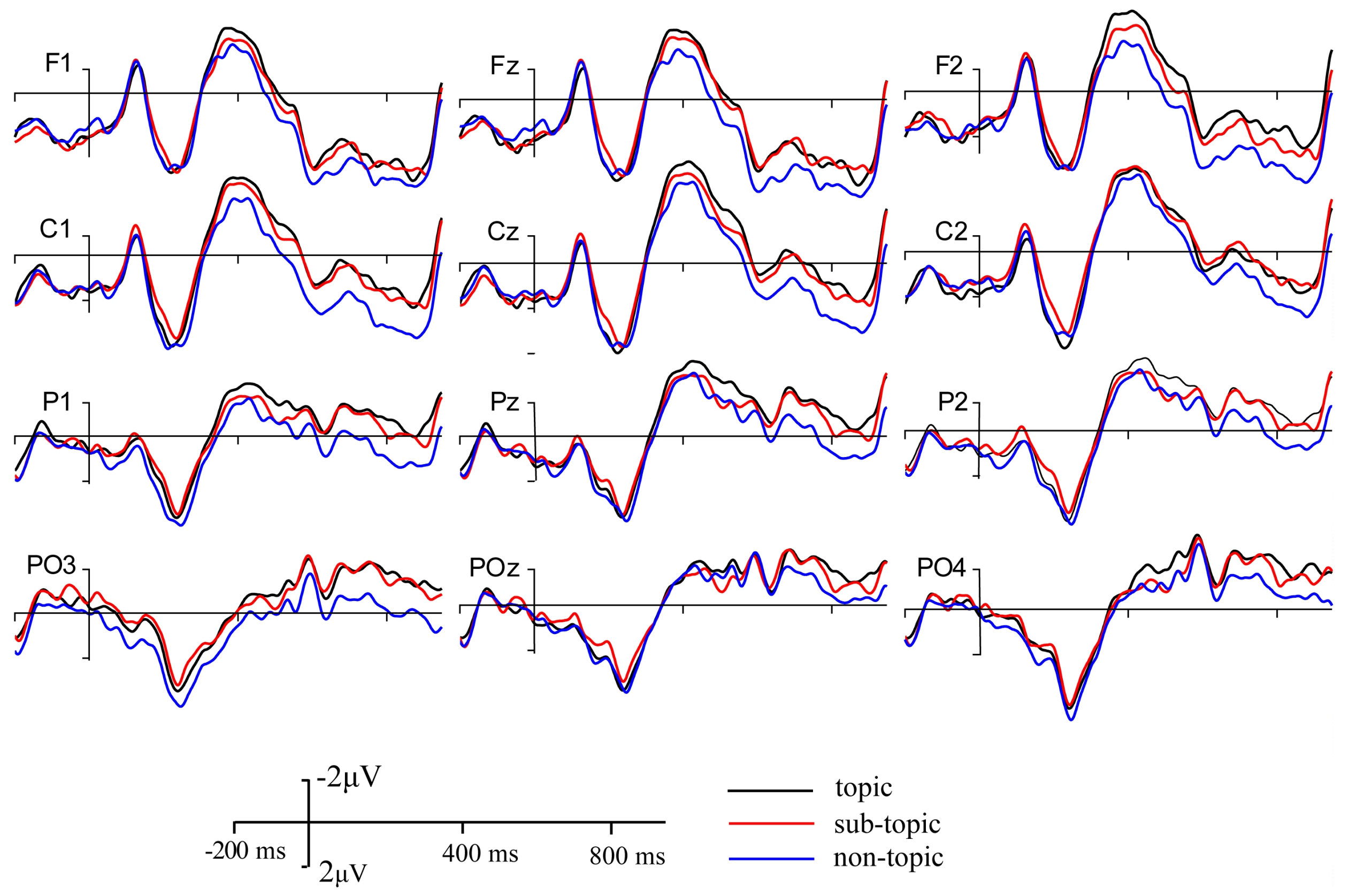


$$
450-800 \mathrm{~ms}
$$

(a)

non-topic vs. topic

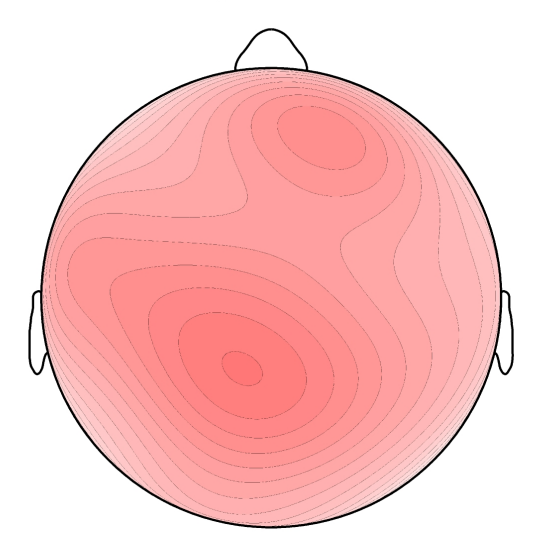

(b)

non-topic vs. sub-topic
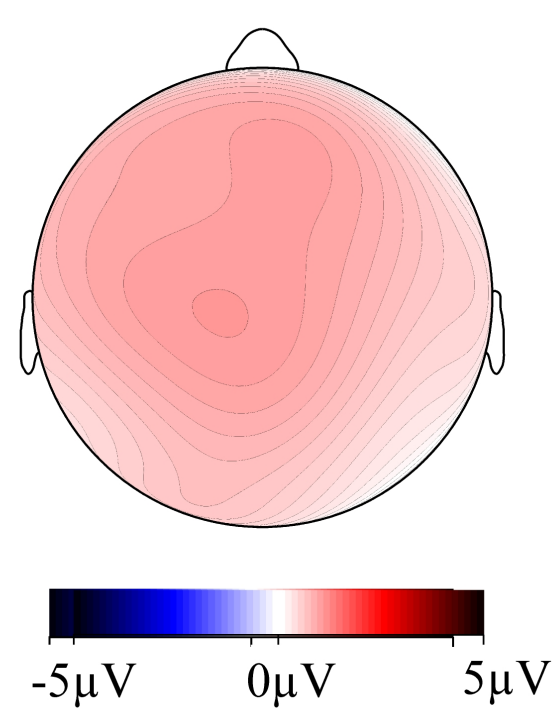

(c)

sub-topic vs. topic

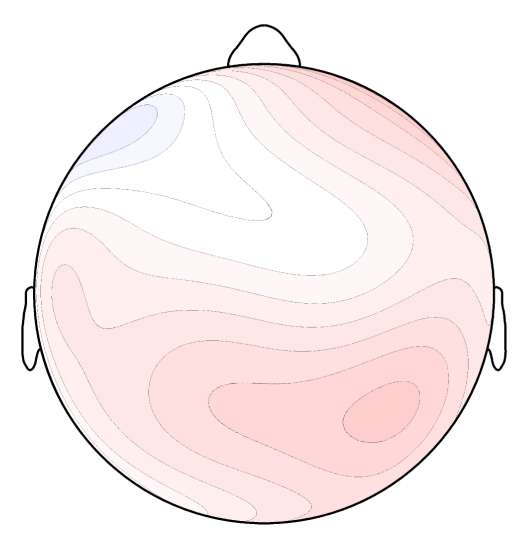

